\title{
The presence of fine sand in the muddy sediments affects habitat selection and accelerates the growth rate of Limnodrilus hoffmeisteri and Limnodrilus claparedianus (Oligochaeta)
}

\author{
Janusz Żbikowski (iD · Elżbieta Żbikowska · Jarosław Kobak
}

Received: 3 September 2020/Revised: 9 April 2021/Accepted: 16 April 2021/Published online: 6 May 2021

(C) The Author(s) 2021

\begin{abstract}
Assessment of food conditions for animals is usually based on the quality and quantity of available food, whereas less attention is paid to other factors affecting the processing of ingested food. One of the commonly used mechanisms involving nondigestible objects from the environment is lithophagy (using swallowed stones or sand grains as gastroliths). Therefore, the aim of this laboratory study was to investigate the impact of sand present in muddy bottom sediments on ubiquitous freshwater oligochaetes: Limnodrilus hoffmeisteri and Limnodrilus claparedianus. They belong to the most common tubificid species and, as detritivores, play crucial role in the functioning of water ecosystems. We showed that the presence of sand in the environment has positive effects on oligochaete habitat preferences and
\end{abstract}

Handling editor: Marcelo S. Moretti

\footnotetext{
J. Żbikowski ( $\square)$

Department of Ecology and Biogeography, Faculty of Biological and Veterinary Sciences, Nicolaus Copernicus University, Torun, Poland

e-mail: jzbikow@umk.pl

\section{E. Żbikowska · J. Kobak}

Department of Invertebrate Zoology and Parasitology, Faculty of Biological and Veterinary Sciences, Nicolaus Copernicus University, Torun, Poland

e-mail: ezbikow@umk.pl

J. Kobak

e-mail: jkob73@umk.pl
}

growth. They selected the mixture of mud and 60-160 $\mu \mathrm{m}$ sand over pure mud and mud with larger sand fractions. Their growth rate was highest in the sediments with an admixture of this sand fraction, and simultaneously the largest number of sand grains of this size was found in their digestive tracts. In our opinion, the oligochaetes used the sand grains to grind the ingested food, which should accelerate digestion and nutrient assimilation, and stimulate their growth rate.

Keywords Oligochaetes · Particle selection · Gastroliths · Feeding $\cdot$ Substratum preference

\section{Introduction}

The assessment of food conditions for animals is usually based on the quality and quantity of available food. However, much less attention is paid to equally important factors affecting the physical possibility of food intake, as well as the rate of its digestion and absorption of nutrients. The former is particularly important for animals with limited possibilities of grinding potential food (e.g. Oligochaeta). Therefore, they should prefer substratum containing food particles of suitable size.

The lack of possibility of pre-shredding the collected food in the oral cavity decreases the contact area 
for digestive enzymes and consequently prolongs the digestive process. That is why animals unable to chew their food exhibit various mechanisms of accelerating the process of food disintegration in their digestive systems. According to Wings (2007), one of the commonly used methods is lithophagy, i.e. deliberate swallowing of stones or sand grains, depending on the body size of the animal, which become gastroliths after their ingestion. The gastroliths can perform several functions in the digestive system: disintegration and mixing of foodstuff (Jackson, 1997; Wings, 2007), cleaning the stomach (Fox, 1995), regurgitation of indigestible parts (King, 1983), removal of objects obstructing the oesophagus (Waite, 2000) and stimulation of the secretion of digestive fluids (McIntosh et al., 1962). They can also help build up secretions to make swallowing easier (Fox, 1976). Moreover, ingested sand grains with attached desired symbiotic microorganisms may help establish normal intestinal microbial flora, alleviate hunger or preserve the stomach shape (Wings, 2007). The gastroliths can also perform some functions not directly related to the operation of the digestive system. They are presumed to serve as storage for minerals (McCarthy \& Skinner, 1977) and ballast helping keep aquatic animals in place (Zwick \& Hohmann, 2005; Wings, 2007).

The above examples, showing beneficial effects of gastroliths on animal life, suggest their deliberate collection. However, it cannot be excluded that they may also get to the gut of animals inadvertently. According to Wings (2007), gastroliths may also be ingested due to pathological reasons, especially in stressful environments. Moreover, accidental ingestion can occur when sand grains are attached to prey organisms, present in their digestive systems or mistaken for prey. Although several different gastrolith functions may operate concurrently, the most commonly proposed functions are related to the digestive system. However, no study has been conducted yet to confirm many of these hypotheses, so their validity has remained doubtful so far.

The results of previous studies on the possibility of selective ingestion of sediment particles by oligochaetes are not clear. Ravera (1955) reported that aquatic worms were not capable of selecting ingested particles. Juget (1979) also indicated that possibilities of oligochaetes to select the ingested particles were limited. It is the particle-size composition that affects the size of swallowed particles, i.e. the more fine particles in the sediments, the more of them in the intestine. The cited author found larger differences in the size of swallowed particles between populations of the same Oligochaeta species living in the granulometrically different sediments than between different species from the same sediments. The inability to select the ingested particles suggests that the presence of sand in bottom sediments may negatively affect the food conditions for deposit-feeding animals such as Oligochaeta, as the presence of sand in their environment automatically reduces the rate of ingestion of organic particles used by these animals as food. On the other hand, Matisoff et al. (1999) indicated the existence of selective feeding on organic-rich, finegrained particles by Branchiura sowerbyi (Beddard, 1892), Limnodrilus hoffmeisteri Claparède, 1962 and Tubifex tubifex (Müller, 1774). Similarly, Rodriguez et al. (2001) reported that Tubifex tubifex do not ingest all sediment particles, but sort them according to size and/or richness in organic matter. Most likely, the ability of Oligochaeta to select sediment particles of different sizes should be considered separately for each species, as Achurra \& Rodriguez (2016) indicated a different feeding behaviour of two syntopic aquatic oligochaete species Rhyacodrilus arenivorus Achurra \& Rodriguez, 2016 and Rhyacodrilus moulis Achurra \& Rodriguez, 2016.

Although it has long been known that the particle size of the bottom sediments affects the taxonomic composition of tubificids (Sauter \& Güde, 1996), the research on their capability of selective ingestion of particles of different sizes has mainly concerned relatively small organic particles used as food (Rodriguez et al., 2001; Ciutat et al., 2006). On the other hand, little attention has been paid to the role of sand, i.e. mineral grains of a diameter $>63 \mu \mathrm{m}$, which have also been found in oligochaete digestive tracts during the studies of their food composition (Moore, 1981; Liu \& Wang, 2007). There is no information, however, whether the occurrence of sand in the intestine is a consequence of non-casual uptake and whether the sand affects the digestive process.

The term "gastrolith" is not suitable for the tubificids since they do not have any special gaster (= stomach) adapted for accumulating and grinding food particles. Nevertheless, in our paper, we decided to use this term, as its meaning is widely known, and we mainly wanted to check whether the oligochaetes 
under study also use sand grains to grind the ingested food.

The aim of the study was to investigate the potential impact of sand present in muddy bottom sediments on two species of ubiquitous freshwater oligochaetes of the Limnodrilus genus: Limnodrilus hoffmeisteri and Limnodrilus claparedianus Ratzel, 1868 (Naididae, Tubificinae). Such a research is needed as both taxa belong to the most common tubificid species (Van Haaren \& Soors, 2012) occurring in high densities in various water bodies. Besides, taking into account that approx. $50 \%$ of primary production is consumed by herbivores and the remaining 50\% enters the detrital pathway (Cyr \& Face, 1993), it is obvious that detritivores, such as tubificids, play an extremely important role in the ecosystem functioning, Thus, the study of unknown biology features of deposit-feeders which, due to their mass occurrence, significantly affect the ecosystem functioning, is necessary. We hypothesized that (1) the aquatic worms would prefer muddy bottom sediments containing sand (or its particular size fractions); (2) they would swallow sand grains; (3) the presence of sand in muddy sediments would accelerate their growth rate.

\section{Materials and methods}

The oligochaetes of Limnodrilus genus were collected from a lowland dam reservoir $(100 \mathrm{~m}$ from the shore line, from the muddy bottom at a depth of $2 \mathrm{~m}$; $\mathrm{N}: 52^{\circ} 37^{\prime} 5.758^{\prime \prime}$; E: $19^{\circ} 19^{\prime} 36.313^{\prime \prime}$ ) located on the Vistula River (Poland). Our earlier studies (Żbikowski unpubl.) have shown that in this part of the reservoir the density of Limnodrilus (approx. 80\% of total Oligochaeta density) was relatively high (several thousands of individuals per square metre), which suggests favourable living conditions for the genus. Thus, it appears likely that individuals used in our experiments were in good condition. In this zone, the individuals of Limnodrilus genus were easy to distinguish from other oligochaetes, as they were the only ones without hair setae. The genus was represented mainly by two species: Limnodrilus hoffmeisteri (55\% of total Limnodrilus density) and Limnodrilus claparedianus $(45 \%)$. It is impossible to distinguish between living immature individuals of these two species, which usually make up the majority of the population. Nevertheless, the purpose of our study was to check whether the presence of sand in the environment affects the food conditions for the pelophilous oligochaetes in general, rather than to focus on particular species.

Muddy bottom sediments were collected at the above-mentioned sampling site. As oligochaetes feed on very small particles (Rodriguez et al., 2001; Ciutat et al., 2006), we used the size fraction of sediments with particle diameter $<20 \mu \mathrm{m}$ as a food source in our experiments. The fraction was isolated by wet sieving.

Sand used in our experiments was taken in the littoral zone of the same reservoir at a depth of $0.7 \mathrm{~m}$ and divided by wet sieving into the following size classes: $60-160 \mu \mathrm{m}, 160-280 \mu \mathrm{m}, 280-480 \mu \mathrm{m}$ and > $480 \mu \mathrm{m}$. Before the experiments, the sand was kept in a dryer at $100{ }^{\circ} \mathrm{C}$ for several hours to get rid of the biofilm from the surface of the grains.

Experiment 1: Ingestion of sand grains by oligochaetes

The aim of the experiment was to test whether Limnodrilus spp. ingest sand at all, and whether there is a relationship between the size of ingested sand grains and body size of oligochaetes based on the width of their 8th body segment measured using a stereo microscope (Jenderedjian \& Unanian, 1987). The experiment was conducted in a glass circular dish (diameter: $11 \mathrm{~cm}$, height: $7 \mathrm{~cm}$ ). We filled the dish with settled, oxygenated (up to $100 \%$ ) dechlorinated tap water. We put $30 \mathrm{~cm}^{3}$ of each sand fraction and $30 \mathrm{~cm}^{3}$ of mud (particle diameter $<20 \mu \mathrm{m}$ ) as food into the dish (all fractions mixed). Then we left the dish for $24 \mathrm{~h}$ to allow resedimentation of the sediments. At the same time, we selected the oligochaetes and kept them during these $24 \mathrm{~h}$ in a dish without sediments to deprive them of food and stabilize their hunger level. On the next day, we added 50 individuals with the 8 th body segment width ranging from 300 to $650 \mu \mathrm{m}$. In this experiment and in the two other experiments described below, the dishes were kept at a room temperature $\left(20^{\circ} \mathrm{C}\right)$, in darkness to prevent the development of algae on the surface of sediments, which could affect the oligochaete behaviour. The experiment lasted for 7 days. Then, we fixed the animals in $4 \%$ formaldehyde. Next, we measured and dissected them to extract their guts. The guts were 
squashed on a microscope slide and the number and sizes of ingested sand grains were determined under a microscope.

In order to calculate actual sizes of the sand grains in each size fraction, we measured 50 randomly selected sand grains from each size fraction under a microscope. The grain size was estimated as a mean diameter (the mean of two perpendicular dimensions, length and width). We estimated the volume of each grain as a volume of a sphere of a given diameter. On this basis, we calculated percentage shares of grain numbers from particular size fractions in the total number of grains in a mixture consisting of the same volumes of all the fractions:

$P_{i}=\frac{n_{i}}{\sum_{k=1}^{n_{i}} V_{k i}} / \sum_{i=1}^{4} \frac{n_{i}}{\sum_{k=1}^{n_{i}} V_{k i}}$,

where $P_{\mathrm{i}}$ is the percentage share of fraction $i$ in the total number of grains in the mixture, $n_{i}$ is the number of measured grains in fraction $i\left(n_{i} \approx 50\right), V_{\mathrm{ki}}$ is the volume of a single grain $k$ from fraction $i, i$ is fraction number (1-4).

In these calculations, we assumed dense grain packing predicted by the Kepler's Conjecture (Hales, 2012), i.e. $74 \%$. irrespective of the grain size.

We counted, measured and estimated volumes (using the same method as for grains in the sediments) of all sand grains found in the dissected oligochaetes. Then we calculated percentage shares of particular size fractions in oligochaete intestines: both volumetrically and in terms of their numbers. Thus, we could test oligochaete selectivity for grain size assuming that they consume them one by one (if so, numbers would matter) or swallow a certain volume around them (if so, volume proportions in the sediments would be important). We compared the percentages of particular size fractions found in oligochaetes with those present in the sediments using randomization tests (run in Microsoft Excel 2013). As single specimens contained usually just a few grains, we pooled grains from all the individuals for this analysis. To test the null hypothesis that oligochaetes consumed sand grains randomly (in the same proportions as those occurring in the sediments), we simulated a random selection of grains (the same number as that found in the oligochaetes: $N=165$ ) from the pool available in the sediments (i.e. with the same volumetric proportions of the size fractions). We repeated this procedure 1000 times and calculated percentages of particular size fractions (by numbers and volumetrically) in the obtained random samples. Then, for each size fraction, we calculated the probability of obtaining (1) the same or lower percentage share as that actually found in the oligochaetes and (2) the same or higher percentage share as that actually found in the oligochaetes. Given the 2-tailed nature of the test, we considered the difference in percentage shares of grain fractions between oligochaetes and sediments as significant at $P<0.025$.

Furthermore, we estimated the size of the mean and maximum sand grain ingested by each oligochaete individual and used non-parametric Spearman rank correlation coefficients (run in SPSS 25.0, IBM Inc.) to check the relationship between the mean grain size and animal size as well as between the maximum grain size and animal size. As the latter correlation turned out significant (see the Results), we further explored its nature by fitting the logarithmic form of the power equation:

$$
\begin{array}{r}
S_{\max }=A * W^{B} \\
\ln \left(S_{\max }\right)=\ln (A)+B * \ln (W)
\end{array}
$$

where $B$ is the allometric coefficient, $A$ is the intercept, $S_{\max }$ is the maximum grain size, $W$ is the width of the 8th body segment (a proxy for oligochaete size).

We used a Reduced Major Axis Regression as both variables were measured with error and followed the normal distribution (i.e. there were not set up a priori by an experimenter). We tested whether the allometric coefficient $(B)$ of the obtained equation was significantly lower or higher than 1 , which would indicate a negative or positive allometry (i.e. slower or faster increase in the maximum grain size ingested relative to the increase in the body size, respectively). We conducted this test in Microsoft Excel 2013 according to formulas by McArdle (1987).

Experiment 2: Habitat selectivity for sand grain size

The aim of the experiment was to test whether the presence of sand grains of different sizes affects the choice of substrate by individuals of Limnodrilus genus. We used circular glass dishes (diameter: $7 \mathrm{~cm}$, height: $4 \mathrm{~cm}$ ) divided into 2 halves with a metal partition, tightly adjacent to the dish walls. We put 
$20 \mathrm{~cm}^{3}$ of pure mud (particle diameter $<20 \mu \mathrm{m}$ ) to one half of the dish and $18 \mathrm{~cm}^{3}$ of mud with an admixture of $2 \mathrm{~cm}^{3}$ of a given fraction of sand to the other half. Positions of particular sand fractions in the dish relative to the laboratory room varied randomly among replicates. Then, we filled the dish with settled oxygenated tap water and left for $24 \mathrm{~h}$ to allow resedimentation of the sediments. After that, we added 10 medium-sized (the $8^{\text {th }}$ body segment width ranging from 400 to $450 \mu \mathrm{m}$, body length of approx. from 2.0 to $3.0 \mathrm{~cm}$ ) oligochaetes to each half of the dish and removed the partition, so that they could move freely all over the dish. Before the experiment, the oligochaetes were kept for $24 \mathrm{~h}$ without sediments. After $48 \mathrm{~h}$, we put the partition again into the dish and counted the oligochaetes in each half of the dish. We ran 10 replicates per each of the four sand fractions.

For each treatment, we calculated the percentage of individuals occupying the muddy substratum with the admixture of the particular sand size fraction and compared it with a theoretical value of $50 \%$ (assuming a random distribution of animals between both substrata) using a one-sample Wilcoxon test (to test the preference for or avoidance of the admixture relative to the pure mud). Moreover, we used a Generalized Linear Model (binomial distribution, log link function, sand size fraction as a categorical independent variable) followed by pairwise contrasts as a post hoc procedure to compare the percentages of individuals occupying substrata with admixtures of various sand size fractions with one another. These tests were run using SPSS 25.0, IBM Inc.

Experiment 3: Growth in sediments of different grain size

Experiment 2 showed that oligochaetes preferred the muddy sediments with the addition of the finest sand fraction (see the results). Therefore, we hypothesized that oligochaetes swallowed the fine sand to use it to grind their food, which should accelerate the digestion and, as a consequence, their growth rate. So, experiment 3 aimed at investigating whether the size of available sand grains affects the growth rate of oligochaetes. We conducted this experiment in circular glass dishes (height $7 \mathrm{~cm}$, diameter $4 \mathrm{~cm}$ ), filled with $18 \mathrm{~cm}^{3}$ of mud (as food) and $2 \mathrm{~cm}^{3}$ of a given fraction of sand. The control treatment was a dish with only muddy substratum without sand. Two oligochaete individuals ( 1 smaller and 1 larger individual; see later) were put into each dish $24 \mathrm{~h}$ after addition of sediments and their sedimentation on the bottom.

We used oligochaetes from two size groups: smaller, with the 8th body segment width ranging from 260 to $290 \mu \mathrm{m}$ and larger, with the 8th segment width of $380-420 \mu \mathrm{m}$. The use of small individuals was due to the fact that the experiment could not last too long because of the small volume of the dish, which would likely limit the growth of the individuals due to oxygen and/or food depletion during a longtime exposure. In turn, the smaller the animal, the higher its relative growth rate, so changes in size can be observed in shorter periods. However, using only small oligochaetes could lead to misleading conclusions due to their difficulty to swallow larger sand grains. Therefore, larger individuals were also used in the experiment. The experiment lasted for 10 days.

The width of the 8th body segment of oligochaetes was measured by means of a stereo microscope at the beginning and at the end of the experiment. After the experiment, we fixed the animals in $4 \%$ formalin and dissected them to count the ingested sand grains. The experiment was replicated 10 times per each sand size fraction.

We compared growth rates of oligochaetes kept in various sediment types using a General Linear Model including categorical independent variables: sand size fraction and oligochaete size (small and large, included as a within-subject factor) as well as their interaction. The dependent variable in this analysis consisted of mean size increments noted in particular experimental dishes for individual oligochaetes. The analysis was followed by post hoc sequential Bonferroni corrected Fisher LSD tests. We used a Generalized Linear Model (Poisson distribution, log link function) with the same terms as shown above to compare the numbers of grains consumed by oligochaetes in various treatments. The analysis was followed by pairwise contrasts used as a post hoc procedure. However, due to technical difficulties, this analysis was conducted using only 5 replicates out of 10 included in the experiment. These tests were run using SPSS 25.0, IBM Inc. 


\section{Results}

Experiment 1: Ingestion of sand grains by oligochaetes

Four sand size fractions mixed in equal volumes $\left(30 \mathrm{~cm}^{3}\right)$ contained mostly $60-160 \mu \mathrm{m}$ grains (87\% of the number of all sand grains), followed by $160-280 \mu \mathrm{m}$ grains (10\%), $280-480 \mu \mathrm{m}$ grains (2\%) and $>480 \mu \mathrm{m}$ grains $(0.3 \%)$. The mean $( \pm \mathrm{SD})$ number of sand grains ingested by oligochaetes was $3.3 \pm 4.2$ grains per individual (range $0-22$ ). Size distribution of sand grains in oligochaete intestines differed significantly from that available in their environment, both volumetrically (Fig. 1a) and in terms of relative numbers (Fig. 1b). Only the 160-280 $\mu \mathrm{m}$ fraction was more common in the animal intestines than outside while the remaining fractions were consumed less often than it could be expected on the basis of their occurrence in the sediments. The only exception was the $280-480 \mu \mathrm{m}$ fraction, for which we observed no significant difference between relative numbers of sand grains found in the intestines and sediments.

Mean size of sand grains ingested by oligochaetes tended to increase with animal size (Fig. 2), but the correlation was non-significant (Spearman rank

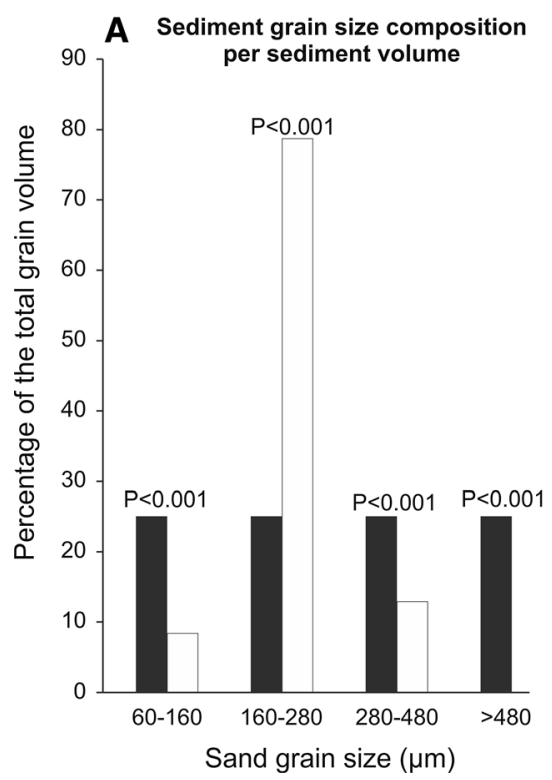

Fig. 1 Ingestion of sand grains of various sizes by oligochaetes exposed to a mixture of volumetrically equal quantities of all grain fractions in the substratum in Experiment 1. $P$ values result correlation: $r=0.28, t=1.80, N=40, P=0.079$ ). On the other hand, maximum size of ingested sand grains was positively correlated with oligochaete size (Spearman rank correlation: $r=0.35, t=2.34$, $N=40, P=0.025$ ), though this relationship seemed to be reversed for the largest individuals (Fig. 2). However, the number of these large oligochaetes was too low to draw any strong conclusions. The relationship between maximum sand grain size and oligochaete size exhibited a slight tendency for positive allometry (indicating the faster increase in the grain size relative to the increase in the animal size), though it was marginally non-significant (Fig. 2).

Experiment 2: Habitat selectivity for sand grain size

Oligochaetes selected more often mud with the addition of the $60-160 \mu \mathrm{m}$ sand fraction compared to pure mud $(<20 \mu \mathrm{m})$ (Fig. 3). The other sand fractions did not affect oligochaete substratum selectivity. Accordingly, the percentage of individuals selecting the $60-160 \mu \mathrm{m}$ sand fraction was greater than those of oligochaetes found in the presence of the other sand fractions (Generalized Linear Model: $\mathrm{F}_{3}, 36=4.64, \quad P=0.008$, followed by pairwise contrasts).

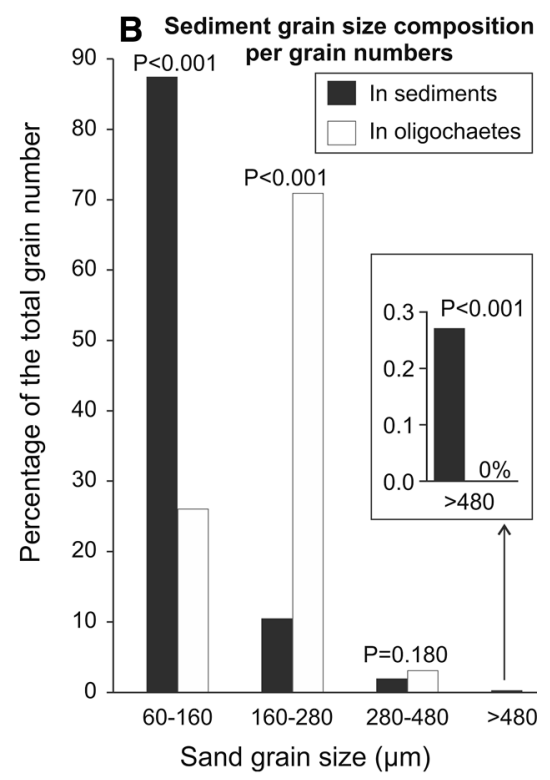

from the randomization tests comparing grain size frequencies in the sediments and oligochaete intestines 
Fig. 2 Relationship between oligochaete size (measured as the width of the 8 th body segment) and diameter of ingested sand grains (mean and maximum) in Experiment 1. Circles show all sand grains ingested by oligochaetes of a given size, with solid symbols indicating maximum grain ingested by a given individual. A dashed line indicates an allometric relationship between oligochaete size and maximum ingested sand grain size (calculated according to the Reduced Major Axis regression model)

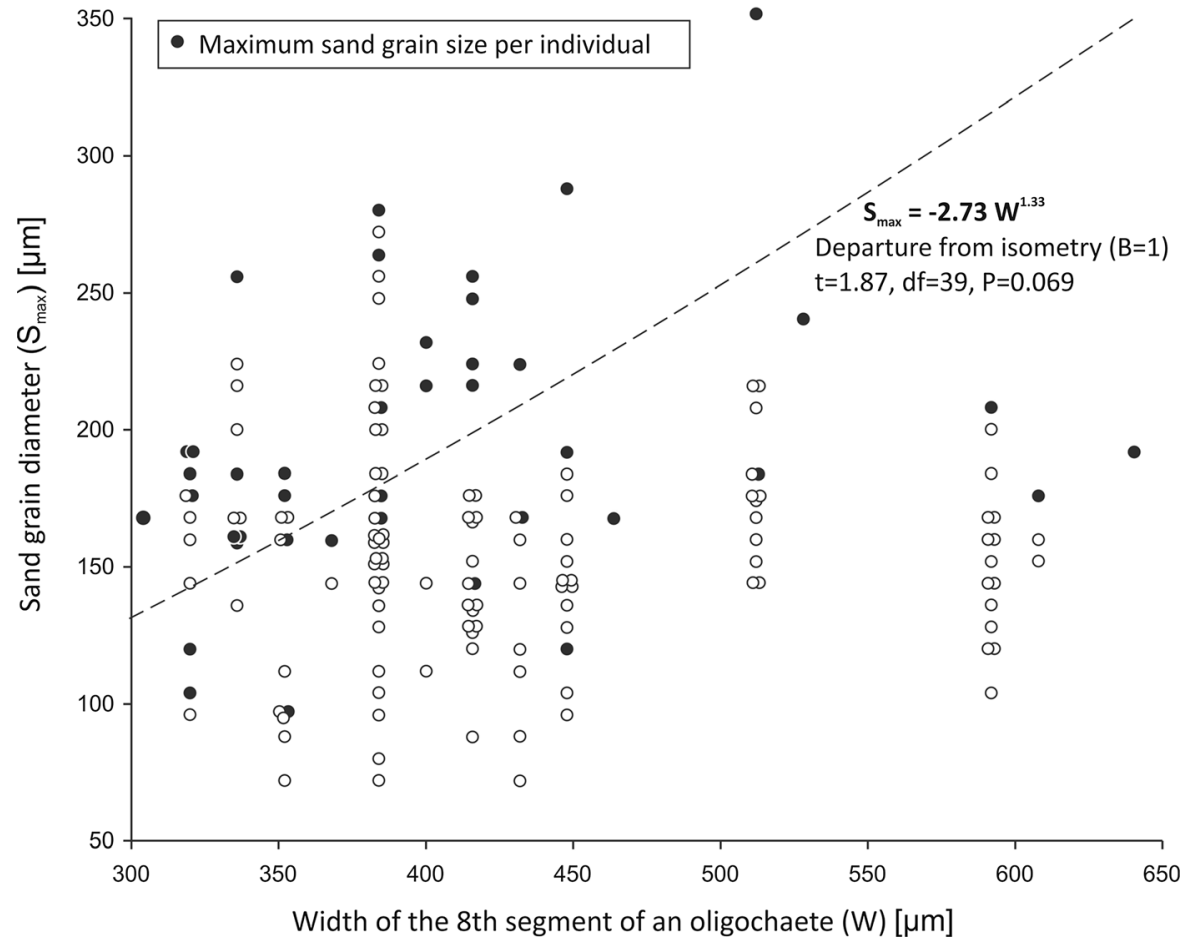

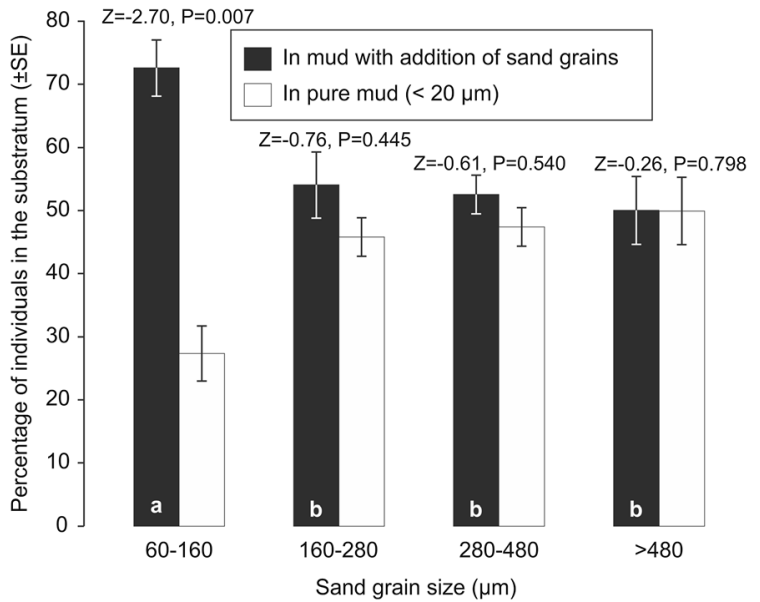

Fig. 3 Habitat selection by oligochaetes depending on the presence of sand grains of particular size fraction in Experiment 2. Oligochaetes could select between two substrata: pure mud and mud with the addition of a particular sand grain fraction. Test results are one-sample Wilcoxon tests checking the departure of oligochaete distribution from a random distribution (50\% in both substrata). Different letters $(\mathbf{a}, \mathbf{b})$ on the bars indicate significant differences between oligochaete occurrences in particular sand fraction treatments (pairwise contrasts of the Generalized Linear Model)
Experiment 3: Growth in sediments of different grain size

The size of sand grains added to the muddy substratum affected oligochaete growth rate, influencing differently animals of various sizes, which resulted in a significant grain size $\mathrm{x}$ oligochaete size interaction in the General Linear Model $\left(\mathrm{F}_{4,89}=6.25, P<0.001\right)$. Smaller individuals exhibited the fastest growth rate in the presence of the 60-160 $\mu \mathrm{m}$ sand fraction and the slowest growth rate in the presence of the largest sand fraction $(>480 \mu \mathrm{m})$ (Fig. 4). Larger oligochaetes performed best in the presence of $60-480 \mu \mathrm{m}$ sand grains, and reduced their growth rate in pure mud and in the presence of the largest sand fraction $(>480 \mu \mathrm{m})$ (Fig. 4).

Oligochaetes consumed more $60-160 \mu \mathrm{m}$ sand grains than those of other sizes (Fig. 5), regardless of animal size (a significant grain size effect in the Generalized Linear Model: $\mathrm{F}_{4,40}=19.96, P<0.001$, non-significant oligochaete size effect: $F_{1,40}=1.19$, $P=0.282$ and their interaction $\mathrm{F}_{4,}, 40=0.90$, $P=0.471)$. The second most commonly consumed sand fraction was that of $160-280 \mu \mathrm{m}$. 


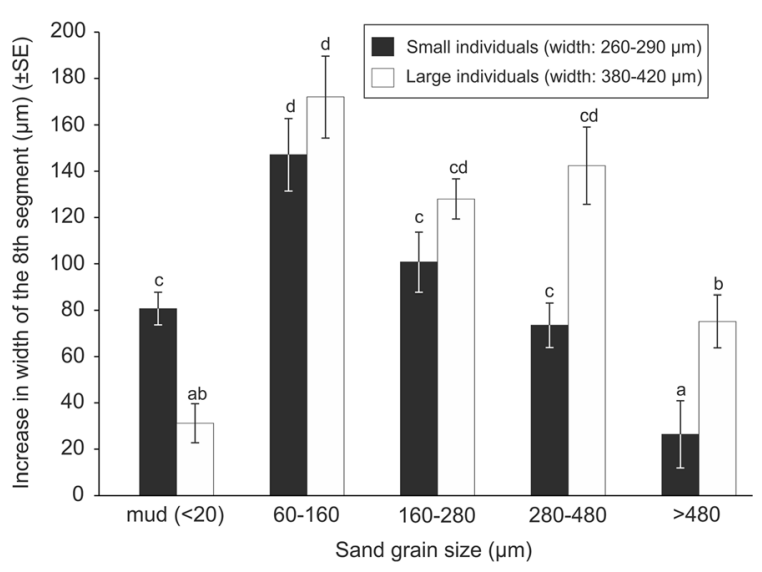

Fig. 4 Oligochaete growth in the presence of various sand grain size fractions and in the pure mud in Experiment 3. Different letters (a-d) above the bars indicate significant differences in oligochaete growth rate between particular treatments and size classes (post hoc procedure of the General Linear Model)

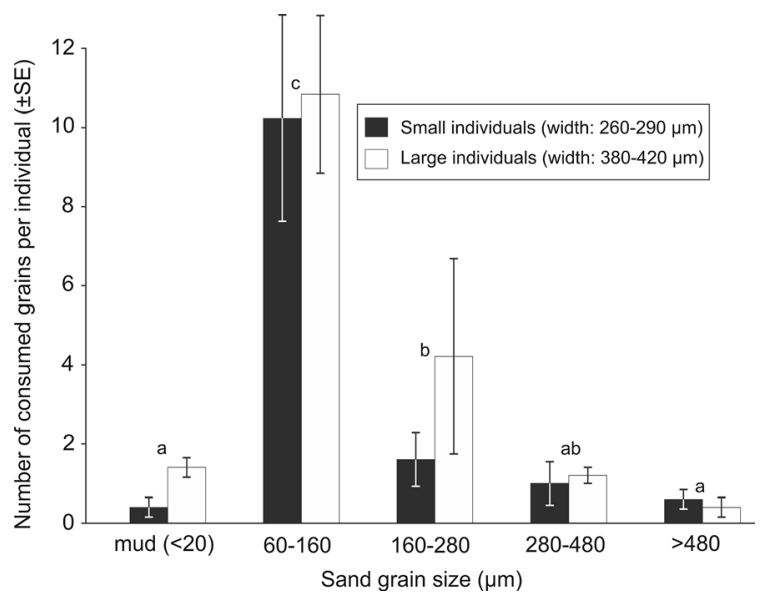

Fig. 5 Ingestion of sand grains of various sizes by oligochaetes in Experiment 3. Different letters (a-c) above the bars indicate significant differences in the number of consumed grains between particular treatments (pairwise contrasts of the Generalized Linear Model)

\section{Discussion}

The results of this study confirmed our assumption that the presence of sand in the environment has positive effects on the food conditions of typical detritivores, such as tubificids of the Limnodrilus genus. These animals chose the sediments containing a given sand size fraction and showed the possibility of selective ingestion of sand grains of the preferred size. Thus, not only the presence of sand in the sediments, but, above all, the grain size plays an important role in oligochaete foraging.

The beneficial effect of fine sand on Limnodrilus hoffmeisteri was demonstrated by Alves \& Strixino (2000) and Lobo \& Alves (2011). The former stated that individuals living in fine sand were more fit and could breed a greater number of offspring in a longer period of time, whereas the latter showed that in fine sand individuals earlier reached sexual maturity, deposited more cocoons and grew faster. In turn, the results of our research contribute to the explanation of the mechanism of the beneficial effect of fine sand on Limnodrilus. Namely, the better physical condition, more effective reproduction and faster growth rate of individuals reported by the above-cited authors could have resulted from improved nutritional conditions faster food grinding due to the presence of fine sand.

In general, larger individuals swallowed larger sand grains, but no statistically significant correlation between body size and average grain size was found. This is most likely due to two reasons: firstly, individuals of different sizes ingested a lot of quite small grains, and secondly, the largest individuals ( $>500 \mu \mathrm{m}$ in diameter) swallowed relatively small grains. The former is not a surprise, because, according to Wings (2007), even smaller grains may have important functions also in larger animals. The second reason may be the fact that the largest individuals, despite the potential morphological possibilities, did not ingest large grains, perhaps due to the deteriorating physical condition at the end of their lives. On the other hand, there may be a certain optimal size of swallowed gastroliths and a further enlargement of their size does not increase the efficiency of food grinding. A similar regularity was found by Zwick \& Hohmann (2005), who observed that the largest larvae of aquatic insect Isoptena serricornis (Pictet, 1841) (Plecoptera) swallowed sand grains smaller than their morphological ability suggested. It should be emphasized, however, that the small number of the largest individuals in our study makes it impossible to draw a reliable conclusion.

Maximum size of sand grains ingested by oligochaetes was positively correlated with oligochaete size. This regularity did not apply to the largest individuals $(>500 \mu \mathrm{m}$ in diameter), in which the maximum size of swallowed grains was relatively small. Similar results were obtained by Juget (1979). It is likely that mouth gape limits the size of grains that 
could be swallowed. The maximum size of sand grains ingested by Limnodrilus spp. in our research reached $300 \mu \mathrm{m}$ (only in one case almost $350 \mu \mathrm{m}$ ) and was slightly larger than the data presented by other authors: $281 \mu \mathrm{m}$ (Juget, 1979), $260 \mu \mathrm{m}$ (Ciutat et al., 2006) or $200 \mu \mathrm{m}$ (Poddubnaja, 1961). It should be noted, however, that these authors did not provide the body width of the individuals, which prevents accurate comparison. As the largest individuals used in our experiments reached almost maximum body size of these taxa, it can be assumed that the maximum size of sand grains that can be swallowed by them is approx. $300-350 \mu \mathrm{m}$ in diameter.

The size of sand grains ingested by oligochaetes in our study was 3-4 times larger than the preferred size of food particles reported by other authors (Rodriguez et al., 2001; Ciutat et al., 2006), which also confirms the ability of aquatic worms to select specific particle types. It is most likely related to the different functions of food and mineral particles. Small food particles have a relatively large surface area accessible to the digestive enzymes, which accelerates the process of digestion and assimilation of nutrients. In turn, the main goal of the swallowed mineral grains is to grind the food and their size is most likely the result of the physical possibilities of oligochaetes to ingest them and associated energy costs as well as the accessibility of mineral grains of given size in the environment.

The results of the first two experiments are contradictory to each other. In experiment 1 , oligochaetes most often ingested sand with a grain size of $160-280 \mu \mathrm{m}$, while in experiment 2 only the $60-160 \mu \mathrm{m}$ sand fraction was selected. It is difficult to explain the difference. Poddubnaja (1961) reported that Limnodrilus hoffmeisteri initially selected food particles and the ingestion of mineral grains (sand) started after some time and its intensity increased with the loss of food particles. If the proportions of the amount of food and mineral particles in the environment affect the feeding of the aquatic worms, it cannot be excluded that the reason for selecting sand grains of different sizes in experiment 1 and 2 could be different proportions of food (mud) and mineral fraction (sand) in both experiments. In experiment 1 , the substrate was dominated by the mineral fraction (sand accounted for $80 \%$ of substrate volume and mud constituted only $20 \%$ of the volume), while in experiment 2 the substrate consisted of $90 \%$ of mud and only of $10 \%$ of a given sand fraction. Thus, when the amount of food is not enough to meet the animal's energy needs, the role of the ingested mineral grains can be extended and, in addition to facilitating the disintegration of food, they are, as suggested by Wings (2007), used for alleviation of hunger and preservation of the stomach shape. In this situation, it seems that larger sand grains are more useful because the animal would have to swallow much more smaller grains for the same effect.

The aim of experiment 3 was to explain the benefits of selecting the substrate with the addition of a given sand fraction in experiment 2 . We hypothesized that the oligochaetes used the sand to grind the ingested food, which should accelerate its digestion and nutrient assimilation, which in turn would stimulate their growth rate. The hypothesis was fully confirmed only for smaller individuals. Their growth rate was the highest in the sediments with an admixture of the finest sand fraction, and simultaneously the largest number of sand grains of this size was found in their digestive tracts. In turn, whereas in the digestive tracts of larger individuals the finest sand grains were also the most numerous, their growth rate in the sediments with the addition of the finest sand was not significantly higher compared to the sediments with the addition of two larger sand fractions, despite the smaller number of swallowed grains of that size. Nevertheless, similar to small individuals, larger oligochaetes did respond positively to the sand admixture, as they grew faster in the presence of sand (all fractions but the largest one) than in the pure mud.

It is difficult to unequivocally explain how swallowing even a small number of sand grains of larger fractions also stimulated the growth rate of oligochaetes. It cannot be excluded that drying the sand before the experiments did not eliminate completely the nutritious fraction (dry algae, bacteria, detritus) adhering to the grain surface. Moreover, the duration of the experiment ( 7 days) could be sufficient for the development of bacterial biofilm on the surface of sand grains. However, taking into account this explanation, it is noteworthy that the amount of food associated with the sand grains would have been relatively small compared to the amount of food contained in muddy sediments $(<20 \mu \mathrm{m})$. This makes the hypothesis on the role of sand particles in grinding food particles more likely than that on their nutritional value. Nevertheless, further research is needed to explain this issue. 
The question still remains open why the larger oligochaetes preferred the sediments containing the finest sand fraction (experiment 2), although their growth rate was also relatively high in the sediments with the addition of larger sand grains (experiment 3 ), which were swallowed to a lower extent. Perhaps sand plays also another role in the oligochaete life besides functioning as gastroliths. These unanswered questions should be an incentive to continue the research initiated by the present study.

\section{Conclusions}

Our study has shown that it is not enough to determine only the quantity and quality of available food to comprehensively assess the food conditions for detritivores, especially those unable to grind the food ingested with their mouthparts. In the case of Limnodrilus taxa, the presence of fine sand in the environment must be also considered. The tubificids under study prefer muddy bottom sediments containing the above-mentioned sand fraction, ingest sand grains and their growth rate is faster under such conditions. It should be assumed that the presence of fine sand in the sediments is not necessary for the life of Limnodrilus spp., but significantly improves their food conditions. Thus, research aimed at assessing the food conditions of the pelophilous oligochaete taxa should also take into account the presence and granulometric composition of the mineral fraction.

Acknowledgements We are grateful to the three anonymous reviewers for their invaluable suggestions that helped us greatly improve the quality of our paper.

Funding No funding was received for conducting this study.

Data availability The data are available at request from the corresponding author.

\section{Declarations}

Conflict of interest We declare no conflict of interest.

Ethical approval No approval is needed for the work on invertebrates in Poland. Our study did not involve research on vertebrates or humans.

Open Access This article is licensed under a Creative Commons Attribution 4.0 International License, which permits use, sharing, adaptation, distribution and reproduction in any medium or format, as long as you give appropriate credit to the original author(s) and the source, provide a link to the Creative Commons licence, and indicate if changes were made. The images or other third party material in this article are included in the article's Creative Commons licence, unless indicated otherwise in a credit line to the material. If material is not included in the article's Creative Commons licence and your intended use is not permitted by statutory regulation or exceeds the permitted use, you will need to obtain permission directly from the copyright holder. To view a copy of this licence, visit http://creativecommons.org/licenses/by/4.0/.

\section{References}

Achurra, A. \& P. Rodriguez, 2016. Syntopy in subterranean fauna: trophic specialisation in two new species of Rhyacodrilus Bretscher, 1901 (Annelida, Clitellata, Rhyacodrilinae). Zoologischer Anzeiger 261: 1-11.

Alves, R. G. \& G. Strixino, 2000. Spatial distribution of Oligochaeta in a marginal lake of the Mogi-Guaçu River, São Paulo, Brazil. Iheringia Série Zoologia 88: 173-180.

Ciutat, A., O. Weber, M. Gerino \& A. Boudou, 2006. Stratigraphic effects of tubificids in freshwater sediments: a kinetic study based on X-ray images and grain-size analysis. Acta Oecologica 30: 228-237.

Cyr, H. \& M. L. Face, 1993. Magnitude and patterns of herbivory in aquatic and terrestrial ecosystems. Nature 361 : 148-150.

Fox, N., 1976. Rangle. Raptor Research 10: 61-64.

Fox, N., 1995. Understanding the Bird of Prey. Hancock House, Surrey, BC.

Hales, T., 2012. Dense Sphere Packings: A Blueprint for Formal Proofs. Cambridge University Press, Cambridge.

Jackson, J. A., 1997. Glossary of Geology. American Geological Institute, Alexandria.

Jenderedjian, K. \& A. Unanian, 1987. Connection between weight and some linear parameters of tubificids on the example of Potamothrix hammoniensis (Michaelsen). In Aquatic Oligochaeta, Riga: 64-66 (in Russian).

Juget, J., 1979. La texture granulometrique des sediments et le regime alimentaire des oligochètes limnicoles. Hydrobiologia 65: 145-154.

King, J. E., 1983. Seals of the World. British Museum (Natural History), London.

Liu, X. Q. \& H. Z. Wang, 2007. Food composition and dietary overlap of macroinvertebrates in a shallow eutrophic lake in China: spatial and temporal variations. Fundamental and Applied Limnology 168: 71-82.

Lobo, H. \& R. G. Alves, 2011. Influence of body weight and substrate granulometry on the reproduction of Limnodrilus hoffmeisteri (Oligochaeta: Naididae: Tubificinae). Zoologia 28: $558-564$.

Matisoff, G., X. Wang \& P. L. McCall, 1999. Biological redistribution of lake sediments by tubificid oligochaetes: Branchiura sowerbyi and Limnodrilus hoffmeisteri/Tubifex tubifex. Journal of Great Lakes Research 25: 205-219.

McArdle, B. H., 1987. The structural relationship: regression in biology. Canadian Journal of Zoology 66: 2329-2339. 
McCarthy, J. F. \& D. M. Skinner, 1977. Proecdysial changes in serum ecdysone titers, gastrolith formation, and limb regeneration following molt induction by limb autotomy and/or eyestalk removal in the land crab, Gecarcinus lateralis. General and Comparative Endocrinology 33: 278-292.

McIntosh, J. I., S. J. Slinger, I. R. Sibbald \& G. C. Ashton, 1962. Factors affecting the metabolizable energy content of poultry feeds. 7. The effects of grinding, pelleting and grit feeding on the availability of the energy of wheat, corn, oats and barley. 8. A study on the effects of dietary balance. Poultry Science 41: 445-456.

Moore, J. W., 1981. Inter-species variability in the consumption of algae by oligochaetes. Hydrobiologia 83: 241-244.

Poddubnaja, T. L., 1961. Materials on the nutrition of mass species of tubificids in Rybinsk Reservoir. Trudy Instituta Biologii Vodokhranilishch 4: 219-231. (in Russian).

Ravera, O., 1955. Amount of mud displaced by some freshwater Oligochaeta in relation to the depth. Symposium on Biological, Physical and Chemical Characteristics of the Profundal Zone of Lakes. Memorie dell'Istituto Italiano di Idrobiologia, Pallanza, Italy, pp. 247-264.

Rodriguez, P., M. Martinez-Madrid, J. A. Arrate \& E. Navarro, 2001. Selective feeding by the aquatic oligochaete Tubifex tubifex (Tubificidae, Clitellata). Hydrobiologia 463: 133-140.
Sauter, G. \& H. Güde, 1996. Influence of grain size on the distribution of tubificid oligochaete species. Hydrobiologia 334: 97-101.

Van Haaren, T. \& J. Soors, 2012. Aquatic oligochaetes of The Netherlands and Belgium. KNNV, Zeist.

Waite, E. R., 2000. II. B Narrative of sub-Antarctic cruises; the vertebrate land fauna. In Shaughnessy, P. D. (ed.), Antarctic Seals, Whales and Dolphins of the Early Twentieth Century: Marine Mammals of the Australasian Antarctic Expedition 1911-14, and the British, Australian and New Zealand Antarctic Research Expedition 1929-31. Australian Antarctic Division, Department of the Environment and Heritage, Tasmania, Kingston: 18-23.

Wings, O., 2007. A review of gastrolith function with implication for fossil vertebrates and a revised classification. Acta Palaeontologica Polonica 52: 1-16.

Zwick, P. \& M. Hohmann, 2005. Biological notes on Isoptena serricornis, an exeptional stonefly in shifting river sand (Plecoptera: Chloroperlidae). Lauterbornia 55: 43-64.

Publisher's Note Springer Nature remains neutral with regard to jurisdictional claims in published maps and institutional affiliations. 